\title{
Longshore suspended sediment transport and its implications for submarine erosion off the Yangtze River Estuary
}

\author{
Bing Deng*, Hui Wu*, Shilun Yang, Jing Zhang \\ State Key Laboratory of Estuarine and Coastal Research, East China Normal University, \\ No. 3663 Zhongshan Road North, Shanghai, P. R. of China, 200062 \\ *These authors contributed equally to this work.
}

\begin{abstract}
Coastal currents that originate from large rivers play a key role in delivering sediment to shelf regions. Quantifying their transport capability is therefore essential to understanding the sediment budgets and the consequent deposition or erosion of coastal areas. In February 2012, we observed the sediment transport carried by the Min-Zhe Coastal Current that originates from the Yangtze River mouth and calculated a flux of $\mathbf{1 8 . 7}$ tons per second on a cross-shore section. In this period the coastal current was at a typical status, which allowed us to estimate a total annual sediment transport of 0.27 billion tons southward. This result was more than three times the present annual Yangtze River sediment discharge, suggesting that considerable net sediment removal occurs in the coastal regions. The sediment transport 0.27 billion tons/year is probably the deposition/erosion threshold for the East China Sea coast north of our study site. Analysis of historical Yangtze River sediment influx records showed, that the onset and acceleration of coastal erosion was closely linked with the operation of the Three Gorges Dam (TGD) upstream of the Yangtze River.
\end{abstract}




\section{Introduction}

Longshore coastal current systems are common on global continental margins, and their influence on the redistribution of terrestrial materials has long been recognized (Shepard, 1932; Geyer, 1995; Lentz and Largier, 2006). Riverine sediment extends hundreds of kilometers downstream of the coastal currents originating from large river mouths (such as the Amazon, Pearl, Yangtze, and Mekong River) (Allison et al., 1995; Geyer, 1995; Liu et al., 2006; Xue et al., 2010). Driven by buoyancy and/or wind (e.g., the seasonal monsoon in Asia or trade winds in South America), coastal currents regulate the efficiency with which terrestrial sediments are trapped and transported within shelf regions (Geyer, 1995; Deng et al., 2006). Over past decades, drop of riverine sediment infill leaded to coastal erosion in delta regions (Smith, 1988; Milliman, 1997; Giosan et al., 2006; Yang et al., 2011; Bergillos et al., 2016), due to unprecedented intensive engineering practices and environmental change. The study of coastal current provide potentially an oceanic perspective for understanding the adjustment of coast systems to river basin change.

The Min-Zhe Coastal Current (MZCC) originates at the Yangtze River mouth, and extends southward along the coast toward the Taiwan Strait. The MZCC is a typical river-induced buoyant coastal current; it is driven mainly by the lateral buoyancy input of the Yangtze River, the surface momentum flux of the downwelling-favorable wind stress, and the rotation effect of the Earth (Wu et al., 2013). During autumn to the following early spring every year, the river discharge is relatively low and the wind is mainly northerly/northeasterly (known as the East Asian Winter Monsoon); these conditions favor the development of a bottom-trapped buoyant coastal current (Yankovsky and Chapman, 1997). The coastal current remobilizes the fine sediments deposited at the Yangtze River mouth during previous flood seasons (Milliman et al., 1985a), thereby forming the longshore mud zone between the Yangtze River mouth and the Taiwan Strait (Shepard, 1932; Niino1961; Milliman et al., 1985a).Although some hydrological observations of this coastal current system have been reported (Zhu et al., 2004; Wu et al., 2013), few direct measurements of its sediment transport capacity have 
been made. As the primary sediment transport pathway off the Yangtze River mouth (Niino1961; Milliman et al., 1985a), the transport capacity of the MZCC is the key to understanding the sediment budget at the river mouth which involves both the sediment supply from the Yangtze River and the flux of sediment transported southward by the MZCC, as well as the deposition or erosion of the delta and adjacent coastal areas. Because the sediment supply to the river mouth declined over recent decades due to hydrological engineering practices in the river basin, increasing erosion has been observed in the coastal regions (Yang et al., 2011). Conventional research efforts for coastal erosion evaluation have relied on long-term morphological monitoring, which is difficult to conduct for large river mouths and at an inter-annual scale because of the large area involved and the subtle yearly morphological variability. In this study, we examined the sediment flux and mechanism of sediment remobilization and transport to investigate the sediment transport capacity of the MZCC and to explain the onset of coastal erosion off the Yangtze River mouth.

\section{Study Site}

The Yangtze River delta and its distal, including the submerged delta and mud zone along Min-Zhe Coast, is located in the east China. The tidal regime is typically semi-diurnal, and the tidal range varies from $2 \mathrm{~m}$ in the inner shelf to $6 \mathrm{~m}$ on the coast, with a maximum tidal range of $8.9 \mathrm{~m}$ in the Qiangtangjiang Estuary. The tidal current velocity in the Changjiang Estuary can reach $200 \mathrm{~cm} / \mathrm{s}$, decreasing eastwards to $50 \mathrm{~cm} / \mathrm{s}$ in the delta front (Bao et al., 2001). The East Asian monsoon dominated, causes prevailing southerly and southeasterly winds, with frequent typhoons in summer, and northerly and northwesterly winds with in winter. The strong tidal current and wind-induced waves result in active sediment resuspension in the coastal regions.

Sediment in the submerged delta is mainly fine grain mud and silt which make the Yangtze delta vulnerable to coastal erosion from sediment reduction in the Yangtze River basin in recent years. Since 1980s, over 30,000 dams was built in its tributaries 
and mainstream, resulting in dramatic drop of sediment supply to the river mouth from 0.5 billion tons to 0.3 billion tons until 2002 (Yang et al., 2005). Upon 2003, the Three Gorges Dam began to operate, as a result, sediment discharge further drop to 0.15 billion ton in year 2010, and 0.071 billion tons in 2011. Degradation of coastal wetland resulted from coastal erosion in response to Changjiang drainage basin change potentially affected ecological and economical service function of coastal sea.

From February to March 2012, we conducted a hydrological and sedimentary survey along the Zhejiang Coast, $200 \mathrm{~km}$ south of the Yangtze River mouth (Fig. 1). Since the Zhoushan archipelagos are on the sediment dispersal pathway and are potentially sediment transport passage, the observation sites were then carefully selected to avoid the influence of the Zhoushan archipelagos and to measure the winter coastal current where it was fully developed (Wu et al., 2013).

Our survey was conducted during the typical northeasterly winter monsoon season, which had an average wind strength of $7.57 \pm 1.66 \mathrm{~m} / \mathrm{s}$. The mean Yangtze River runoff during the survey period was $15.7 \pm 1.1 \times 10^{3} \mathrm{~m}^{3} / \mathrm{s}$ (Wu et al., 2013). This value was close to the mean Yangtze River runoff from October to March after the Three Gorges Dam (TGD) began operating in 2003, which was reported to be $16.8 \pm 5.9 \times 10^{3}$ $\mathrm{m}^{3} / \mathrm{s}$ by the Yangtze River Water Resource Commission at Datong Hydrographic Station (located $630 \mathrm{~km}$ from the river mouth) (Wu et al., 2013). Tide motion is active in this area, with a maximum surface tidal current speed of $\sim 1 \mathrm{~m} / \mathrm{s}$. The tide type is regular semidiurnal, and the $\mathrm{M}_{2}$ constituent is dominant (Wu et al., 2013).

\section{Methodology and Sampling}

During the cruise survey (5 to 14 February 2012), a downward-looking acoustic Doppler current profiler (ADCP, Teledyne RD Instrument) with a working frequency of $300 \mathrm{kHz}$ was used for current measurements at a $1 \mathrm{~m}$ vertical resolution. The sampling interval was set at $4 \mathrm{~s}$, and at least 5 minutes of data were collected at each site. After averaging in the measuring period, the high-frequency velocity oscillations generated 
by the waves and the ship's pitch and roll were filtered out. The ADCP provided a data quality greater than 95\% for all sites. An Optical Backscatter Sensor (OBS-3A, Campbell Scientific) was used for measuring the water temperature, salinity, and turbidity. Three to four layers of water samples at each stations were collected to measure the suspended sediment concentration (SSC), using water filtration with a 0.45 $\mu \mathrm{m}$ pore size filter membrane. The turbidity data (recorded as Nephelometric Turbidity Unit (NTU)) were then calibrated with data from water samples and finally converted to the SSC (mg/L) to get a vertical resolution up to $1-2$ meters per read. An excellent positive correlation $\left(\mathrm{R}^{2}\right.$ better than 0.95$)$ between the NTU and SSC was obtained. The subbottom data was acquired in August 2013 using an EdgeTech 512i Chirp sonar (EdgeTech Corp.). The acquired data were processed following the recommendations of Liu et al. (2007) using an acoustic velocity of $1500 \mathrm{~m} / \mathrm{s}$ to calculate depth and sediment thickness.

As the study area is strongly affected by tidal currents, a Phase-Averaging Method (PAM) (Wu et al., 2013) was employed to remove tidal signals in the cruising survey along sites 1 to 8 before determining the sub-tidal sediment transport of the MZCC. Since the periodic tidal components are the combination of a series of constituents with similar or doubled periods, they can be removed by repeated sampling for $M$ times with an interval of $(k / M) T$. Here $T$ is the period of the dominant tide constituent, $M_{2}$ in East China Sea; $k$ is a selected even integer that satisfies $\bmod (k, M) \neq 0$. In this study we used an $M$ value of 3 and $k$ equal to 4, resulting in an interval of 16.56 hr. The average obtained by three sampling procedures can satisfactorily remove the tidal signal and provide the sub-tidal current, SSC, and other oceanic properties. A detailed discussion, including the description and errors of this method are published by Wu et al. (2013). The PAM survey was not conducted along the other two transects due to sea condition and operational difficulties.

The mooring observations were performed during 20-28 March 2012. The sampling and data acquisition strategy was similar with the cruise in February, except that the ADCP was installed at $1 \mathrm{~m}$ depth below sea surface. Turbidity data and water 
samples were collected for at least $25 \mathrm{hr}$ with $1 \mathrm{hr}$ interval. Mooring observations were conducted at shallow sites 0,1 , and 2 over at least a complete tidal cycle. Though the temporal and spatial coverage of data are insufficient for a flux calculation and thus a further comparison, the dynamics for sediment resuspension and transport are the same with that of the cruise survey.

\section{Results}

Based on our measurements, the MZCC flowing southward (with longshore speed of $40-45 \mathrm{~cm} / \mathrm{s}$ at its center, Figure 2D) was characterized by lower salinity, lower temperature, and higher suspended sediment concentration (SSC) when compared with the outer shelf water. The coastal current was constrained inshore within a water depth of 40m (Figure 2A, B, and C). Diluted coastal water was found inshore, with the salinity increasing from 27 to 34 . Sites with a water depth greater than $40 \mathrm{~m}$ had a salinity $>34$ (Figure $2 \mathrm{~A}$ ). The temperature increased linearly from $8^{\circ} \mathrm{C}$ offshore to $14^{\circ} \mathrm{C}$ at the front of the coastal current (Figure 2B).The maximum SSC $(800 \mathrm{mg} / \mathrm{L})$ was recorded at shallow site 0at a water depth of $11 \mathrm{~m}$ (Figure 3), and the SSC value decreased seaward to $<10 \mathrm{mg} / \mathrm{L}$ at sites with water depths of $40 \mathrm{~m}$ (Figure 2C). In the vertical, the SSC increased dramatically with depth, ranging from 200 to $800 \mathrm{mg} / \mathrm{L}$ at site 0 , for example (Figure 3).

To the east was the Taiwan Warm Current (TWC), which is a northward flowing shelf current (with a longshore speed of $5-15 \mathrm{~cm} / \mathrm{s}$, Figure 2D) with higher salinity (>34), higher temperature, and lower SSC (Figure 2A, B, C) when compared with the MZCC. The TWC dominated at sites with a water depth $>40 \mathrm{~m}$. The measured temperature was $>14^{\circ} \mathrm{C}$ within its center stream (Figure 2B). The iso-surfaces of salinity and temperature (and therefore density) intersected the sea floor at a large angle, indicating that MZCC is a bottom-trapped buoyant coastal current (Yankovsky and Chapman, 1997). Due to strong tidal mixing, the front was less-sharp than those of the typical bottom-trapped ones, which reduced the transport capacity (Wu et al., 2013). 
The SSC decreased from $<10 \mathrm{mg} / \mathrm{L}$ near the front and to $<1 \mathrm{mg} / \mathrm{L}$ in the center of the flow (Figure 2C). A notable SSC gradient was also found at the interface of the MZCC and the TWC. The bottom SSC declined from $50 \mathrm{mg} / \mathrm{L}$ on the MZCC side to $<10 \mathrm{mg} / \mathrm{L}$ on the TWC side (Figure 2C), which indicated no substantial suspended sediment penetration through the current front.

Similar characteristics of salinity, temperature, and SSC were observed on the other two cross-shelf sections,ECD1-4 and ECB1-6, which were surveyed with a one-way cruise (Figure 2, Figure 4 and Figure 5).The temperature, salinity, and SSC showed identical ranges and tendencies as those on profile 1-8 (Figure 2, Figure 4 and Figure 5). The similarity was also observed on the MZCC and the TWC interface, where the gradients of temperature, salinity, and SSC were similar at the same water depth of approximately $40 \mathrm{~m}$. This implied the dynamics and strength of the MZCC current were relatively constant within this straight shelf.

During mooring observations, tidal asymmetry of SSC was found in the shallow region with water depth $<20 \mathrm{~m}$ (sites 0 and 1) (Figure 3A, B). A high SSC dominated during the ebb tide when turbid coastal water was driven offshore, whereas a low SSC occurred within the flood tide as less turbid outer water was driven onshore (Figure 3A, B). This asymmetry of the SSC drove a seaward sediment transport. Conversely, at the relatively deeper site $2(>20 \mathrm{~m}$ ) (Figure 3C), the SSC was symmetrical for the flood and ebb tides. This offshore sediment transport tendency in shallow areas suggested that sediment remobilization likely took place inshore of the $20 \mathrm{~m}$ isobaths, and tidal asymmetric transport played an important role. A similar mechanism of sediment remobilization was presumably responsible for coastal erosion in the Yangtze Subaquatic delta area when the sediment influx of the Yangtze River declined in recent years because it has the same slope (e.g., 1/2000 to 1/1000) and similar tidal regime as our study sites. This premise is consistent with results of a previous study of the long-term morphological changes of the Yangtze River mouth, in which sediment erosion was found at isobaths of $5 \mathrm{~m}$ to $10-20 \mathrm{~m}$ in recent years (2002-2007)(Yang et al., 2011). 
The total volume flux of the southerly coastal current across sites 1-8 was

calculated to be $0.215 \mathrm{~Sv}$, which is approximately an order of magnitude greater than that of the Yangtze River fresh water discharge (Wu et al., 2013). The sediment flux was calculated as follows:

$$
S F=\underset{A, v<0}{v} v S S C d A
$$

where SF is the sediment flux $\left(\mathrm{g} / \mathrm{m}^{2} / \mathrm{s}\right)$, v refers to the measured residual velocity normal to the cross-section, the SSC represents suspended sediment concentration, and $d \mathrm{~A}$ is the area of each grid (grid size of $2 \mathrm{~m} \times 10 \mathrm{~km}$ ).

The longshore southward coastal current extended seaward to a water depth of $40 \mathrm{~m}$ (35 km offshore, site4) within the study area (Figure 2E). A high sediment flux ( $>40 \mathrm{~g} / \mathrm{m}^{2} / \mathrm{s}$ ) occurred in water at depths of $17-24 \mathrm{~m}$, with a maximum of $70 \mathrm{~g} / \mathrm{m}^{2} / \mathrm{s}$ at water depths of 20-22 m (Figure 2E), where both high turbidity and a strong alongshore coastal current were recorded. The sediment flux decreased onshore from $70 \mathrm{~g} / \mathrm{m}^{2} / \mathrm{s}$ in the main stream coastal current to $6 \mathrm{~g} / \mathrm{m}^{2} / \mathrm{s}$ at a water depth of $12 \mathrm{~m}$ (site 1). A low sediment flux was also observed offshore to the boundary with the TWC. A total longshore sediment flux of 18.7 tons/s was estimated by integrating the sediment flux over the coastal current. The suspended sediment transport center $\left(>40 \mathrm{~g} / \mathrm{m}^{2} / \mathrm{s}\right)$ spanned approximately $12 \mathrm{~km}$, accounting for $65 \%$ of the total sediment transport by the coastal current. Conversely, the onshore portion of the coastal current (in 12-17 m water depth) represented only $7 \%$ of the southward sediment transport. Moving offshore from the transport center (to $24-40 \mathrm{~m}$ water depth) added up to $28 \%$ to the sediment transport.

The cross-shore component of sediment flux was directed eastward at a water depth of $<20 \mathrm{~m}$, decreasing from $30 \mathrm{~g} / \mathrm{m}^{2} / \mathrm{s}$ near the coast to $0 \mathrm{~g} / \mathrm{m}^{2} / \mathrm{s}$ at $20 \mathrm{~m}$ depth (Figure 2F). There were a number possibilities that caused this offshore transport, such as the Ekman effect of downwelling-favorable wind, and bottom Ekman effect of buoyant coastal current (Chapman and Lentz, 1994). This offshore transport along with the tidal asymmetric SSC carried the sediments from the shallow water area toward the 
mainstream of the alongshore coastal current, which was a key mechanism for sediment remobilization.

Further offshore (depth>20 m), the sediment flux exhibited an onshore trend with a rate of $5-2 \mathrm{~g} / \mathrm{m}^{2} / \mathrm{s}$ (Figure $2 \mathrm{~F}$ ). This may be the result of the bottom Ekman effect induced by the northward flowing TWC, which turns the bottom velocity left towards the coast (Lü et al., 2006). This retained sediment in the mainstream current, and kept it from penetrating further offshore.

\section{Discussion}

As a buoyant coastal current, the MZCC is essentially determined by the bathymetry of the East China Sea coast (Yankovskyand Chapman, 1997) and modulated by dynamic factors, especially freshwater discharge and wind. The volume transport of MZCC was mainly determined by the reduced gravity of the plume water, which was insensitive to slight short-term river discharge fluctuations, while the direct wind stress contributes about the rest $40 \%$ (Wu et al., 2013). More importantly, the wind effect was demonstrated to be linear and instant (Huang et al., 2015). Hence, the effect of short-term fluctuation of wind stress can be largely smoothed out after averaging in the winter monsoon season. In the past 12 years, the winter north-northeasterly wind duration and mean strength were $164 \pm 9$ days and $7.55 \pm 0.29$ $\mathrm{m} / \mathrm{s}$, respectively, and both exhibited weak inter-annual variation (The winter wind data was from the ECMWF). These imply that, on the long-term scale, the annual volume transport of MZCC was relatively stable, unless the topography was substantially changed, which can happen only on a geological time scale that is beyond our focus.

Sediments carried by MZCC were mostly locally resuspended. The sediments in the Yangtze River subaqueous delta and alongshore mud zone are fine-grained silty mud (median size of $<15 \mu \mathrm{m})($ Keller and Ye, 1985; Luo et al., 2012; Xu et al., 2012) with high water content $(>50 \%)(\mathrm{Wu}, 2014)$ and low critical shear stress for erosion $\left(\tau_{c r}\right)$ $(<0.1 \mathrm{~Pa})(\mathrm{Wu}, 2014)$. Under the strong tidal regime of the Yangtze River subaquatic delta (i.e., tidal range $2.5 \mathrm{~m}$ and tidal current $\sim 1 \mathrm{~m} / \mathrm{s}$ ) (Sternberg et al., 1985; Shi et al., 
2012), the delta deposits can be easily resuspended and transported away. A comparison of sediment composition for before and after the TGD began operation revealed no obvious grain size change in most of subaquatic delta areas (Keller and Ye, 1985; Luo et al., 2012).Moreover, the sedimentary profile along the subaquatic delta revealed that fine grain sediment dominated during the Holocene and formed a $20-40$ $\mathrm{m}$ thick mud wedge (Figure 1) (Liu et al., 2006; Xu et al., 2012). The remobilization of sediment from the mud coast served as a steady source for coastal current sediment transport, which was insensitive to the recent variation of the Yangtze River sediment discharge.

Potential sources of sediment influx for the East China Sea coast include the Yangtze River, the sediment from the Yellow Sea, and other small rivers (Milliman et al., 1985b; Qin et al., 1996). Historically, the Yangtze River carried $\sim 0.5$ billion tons of sediment annually to the East China Sea. Most of these sediments settle at and near the river mouth during summer (i.e., within $100 \mathrm{~km}$ of the inshore area) (Milliman et al., 1985a; Sternberget al., 1985; Bian et al., 2013). In the winter, a large quantity of deposited sediments are resuspended and transported southward by the longshore current driven by the prevailing north-northeasterly winds (Demaster et al., 1985; Milliman et al., 1985a). Sediments from the Yellow Sea are transported southeastward by the Yellow Sea Coastal Current (Figure 1)and join with the TWC in the northern East China Sea, which drains eastward to the Tsushima Strait (Milliman et al., 1985b; Qin et al., 1996; Bian et al., 2013). Thus, the distribution of these sediments is mostly constrained within the middle and the outer shelves. Other rivers along the coast of the East China Sea contribute less than 10 million tons of sediment annually, and most of this material is trapped within the estuary (Deng et al., 2006). Therefore, the dominant sediment source in our measurement transects was the resuspended and remobilized sediments from the Yangtze River mouth. Hence, we can evaluate the deposition/or erosion of the Yangtze subaquatic delta and adjoined coastal area by estimating the difference between the Yangtze River sediment influx to the river mouth and sediments transported southward by MZCC. 
We measured the first reported MZCC sediment flux that was 18.7 tons/s, under typical average wind strength and river discharge conditions for the winter season. The wind strength during our measurement $(7.57 \pm 1.66 \mathrm{~m} / \mathrm{s})$ are closed to decade average as analysis above $(7.55 \pm 0.29 \mathrm{~m} / \mathrm{s})$, thus we can further extrapolate our result. If extending this transport rate to the entire winter monsoon season, the estimated sediments transport was $\sim 0.27$ billion tons/year in the past decade (Figure 6). This was calculated using the equation $\mathrm{Q}_{\mathrm{sf}}=\mathrm{SF} \cdot t$, where $\mathrm{SF}$ is the integrated sediment flux over coastal current transection (tons/s) and $t$ is time (164 days, the mean length of the winter monsoon season). As the near-coast currents are much weaker in the summer season, we considered this value to be representative of the annual transport capacity. It reflected the typical sediments transport capacity of the MZCC under the normal atmospheric and oceanic conditions. When compared with the historical Yangtze River sediment discharge, the sedimentation in the Yangtze River mouth and the adjoining coast attained a balance during 2001-2002, when the Yangtze River sediment discharge declined to approximately $0.27-0.26$ billion tons, which was equal to the amount of annual sediment transported by the coastal current (Figure 6). The onset of net coastal erosion began presumably in 2003 , when the sediment supply to the river mouth decreased to 0.205 billion tons immediately following the operation of the Three Gorges Reservoir (with a water storage capacity of 39.3 billion $\mathrm{m}^{3}$ ) on the main channel of the Yangtze River (Figure 6). From 2006 to 2008, the sediment discharge declined to 0.14 billion tons/year due to the higher water level operation of the TGD (156 m), and as a result the net erosion accelerated to 0.13 billion tons/year. When the TGD operation reached full capacity (171-175 m from 2008 to present day), the net coastal erosion approached its current maximum of 0.20 billion ton/year (measured in 2012) to balance the sediments transport by the MZCC.

Therefore, 0.27 billion tons/year was considered the threshold of sediments discharge from the Yangtze River, below or above which would cause the erosion or deposition in the Yangtze River subaqueous delta and alongshore mud zone. This threshold agreed with the calculation that Yang (2011) made using a long-term 
morphological regression. Moreover, a highly significant positive linear correlation between the Yangtze River sediment load and subaqueous delta accumulation/erosion was found over the past 50 years (Yang et al., 2011). This finding implied the presence of a stable annual sweep of sediment from oceanic forces, presumably due to coastal current sediment transport. However, Yang et al. (2011)'s calculation was based on an area of subaquatic delta, whereas our result represented a larger area ranging from our measurement site to the Yangtze River mouth. DeMaster (1985) and Shen (1986) suggested sediment accumulated in the subaqueous delta accounted for 200 million t/year (100-year time scale) and 250 million t/year (from 1958 to 1978) respectively, and the remaining sediment was transported and accumulated further south along dispersal system (e.g. 290 and 240million t/year respectively). Longshore sediment transport exhibits less variations from inter-annual to centennial scale, implying a stable longshore sediment transport not controlled by the Yangtze River sediment discharge. Based on mass balance calculation, Milliman et al., (1985a) estimated the southward sediment transport immediately off the Yangtze River mouth to be 150million $\mathrm{t} /$ year, which is lower than our estimation. The difference is possibly related to sediment erosion along the southern distal Yangtze subaqueous delta. Besides, chirp sonar measurement performed by Liu et al. (2007) estimated the longshore sediment transport to be 77 million t/year, on a millennial scale. This millennial scale estimation is lower than our result, and is probably caused by morphological variations due to sea level fluctuation during the Holocene.

The uncertainty in our sediment transport estimated is attributed to the wind wave effect on sediments resuspension, which is a nonlinear response to the wind stress in shallow tidal flat (Shi et al., 2012). Whereas, the similar SSC distribution with depth and distance offshore for all three of the cross-shore sections suggest a less sensitive response to short-term wind variation in the mainstream current. Since the water depth there was relatively large, the local wave-driven sediments resuspension was probably negligible. Besides to the MZCC sediment transport in winter, typhoon induced sediment transport is a potential sediment pathway during summer. In 2006, our survey 
data allow an estimation of typhoon induced cross shelf sediment transport, accounting for $<4 \%$ of the total annual sediment influx (Deng et al., 2006). Nevertheless, we are still unable to fully quantify all processes involved.

\section{Conclusions}

For the northerly wind prevailing season, the coastal current sediment transport flux was estimated at 18.7 tons/s, which was more than three-fold higher than that of the recent Yangtze River annual sediment discharge, indicating severe sediment erosion in the East China Sea coastal region. Significant sediment disturbance and cross-shore transport into the main stream coastal current occurred in the shallow water area, where sediment remobilization most likely dominated. The strong longshore coastal current along with prohibited offshore sediment transport from the TWC maintained the high sediment trapping efficiency of the inner shelf along the East China Sea coast and ensured the alongshore coastal current remained the predominant sediment dispersal path off the Yangtze River. The low fluctuation in both the annual average strength and duration of the driving force, the East Asia Winter Monsoon, along with erodability of sediment, indicated that the inter-annual longshore sediment transport of the coastal current was relatively less fluctuated. The estimated deposition/erosion threshold of 0.27 billion tons/year from the coastal current sediment transport enabled us to further evaluate historical trends of morphological changes to the coast. The onset and acceleration of coastal erosion was closely linked with the operation of the TGD upstream of the Yangtze River. Our results allowed the evaluation of coastal erosion based on past changes, as well as the assessment of the projected influence of the river basin engineering practices in the future. Beyond the TGD, several large dams, including Xiangjiaba and Xiluodu (with water storage capacities of 12.6 billion $\mathrm{m}^{3}$ and 12.8 billion $\mathrm{m}^{3}$, respectively), are under construction or are in the planning stages. Therefore, intensive exploitation will continue to further alter vulnerable coastal ecosystems. 
Although, the driving force, the winter northerly wind, was relatively stable in annual average strength and variation range during the last decade in our study area, in the long run, the change tendency of strength and sediment transport capacity of coastal current is unknown under the context of climate change. Moreover, with the ongoing erosion of the Yangtze subaquatic delta, to what degree and when the morphological adjustment should influence the sediment availability is still uncertain. However, the limitation of our knowledge on this coastal current system is also obvious. Although our estimation on its sediment transport and consequent coastal erosion borrowed countercheck from long-term morphological research well, the kinetic mechanism for sediment resuspension and transport in this coast of morphological complexity was far from well documented, especially the sediment dynamics concerning current-wave interaction and short term storm. Therefore, it is advised that more efforts should be given to studies on the variation of this coastal current system in different time scales.

\section{References}

Allison, M.A., Nittrouer, C.A., Kineke, G.C., 1995. Seasonal sediment storage on mudflats adjacent to the Amazon River. Mar. Geol. 125, 303-328.

Bian, C.W., Jiang, W.S., Quan, Q., Wang, T., Greatbatch, R. J., Li, W., 2013. Distributions of suspended sediment concentration in the Yellow Sea and the East China Sea based on field surveys during the four seasons of 2011. J. Marine Syst. 121, 24-35.

Bergillos, R.J., Delgado, C.R., Millares, A., Ortega-Sanchez, M., Losada, M.A., 2016. Impact of river regulation on a Mediterranean delta: Assessment of managed versus unmanaged scenarios. Water Resources Research, 52, 5132-5148.

Chapman, D.C., Lentz, S. J., 1994. Trapping of a coastal density front by the bottom boundary layer. J. Phys. Oceanogr. 24, 1464-1479.

Demaster, D.J., Brent, A.M., Charlis, A.N., Qian, J., Chen, G., 1985. Rates of sediment 
accumulation and particle reworking based on radiochemical measurements from continental shelf deposits in the East China Sea. Cont. Shelf. Res. 4, 143-158.

Deng, B., Zhang, J., Wu, Y., 2006. Recent sediment accumulation and carbon burial in the East China Sea. Global Biogeochem. Cy. 20, doi:10.1029/2005GB002559.

Geyer, W.R., 1995. Tide-induced mixing in the Amazon frontal zone. J. Geophys. Res. 100, 2341-2353.

Giosan L., Constantinescu S., Clift P.D., Tabrez A.R., 2006. Danish M., Inam A., Recent morphodynamics of the Indus delta shore and shelf. Continental Shelf Research, $26,1668-1684$.

Huang, D.J., Zeng, D.Y., Ni, X.B., Zhang, T., Xuan, J.L., Zhou, F., Li, J., He, S.Y.,2015. Alongshore and cross-shore circulations and their response to winter monsoon in the western East China Sea. Deep-Sea Res. Pt. II. doi/10.1016/j.dsr2.2015.01.001.

Keller, G., Ye, Y.C., 1985. Geotechnical properties of surface and near-surface deposits in the East China Sea. Cont. Shelf. Res. 4, 159-174.

Lentz, S.J., Largier, J., 2006. The influence of wind forcing on the Chesapeake Bay buoyant coastal current. J. Phys. Oceanogr. 36, 1305-1316.

Liu, J.P., Li, A.C., Xu, K.H., Velozzi, Z.S., Yang, Z.S., Milliman, J.D., DeMaster, D.J.,2006. Sedimentary features of the Yangtze River-derived along-shelf clinoform deposit in the East China Sea. Cont. Shelf. Res. 26, 2141-2156.

Liu, J.P., Xu, K.H., Li, A.C., Milliman, J.D., Velozzi, D.M., Xiao, S.B., Yang, Z.S., 2007. Flux and fate of Yangtze River sediment delivered to the East China Sea. Geomorphology, 85(3-4), 208-224.

Lü, X., Qiao, F., Xia, C., Zhu, J., Yuan, Y., 2006. Upwelling off the Yangtze riverestuary in summer. J. Geophys. Res. 111, doi:10.1029/2005JC003250.

Luo, X.X., Yang, S. L., Zhang, J., 2012. The impact of the Three Gorges Dam on the downstream distribution and texture of sediments along the middle and lower Yangtze 
River (Changjiang) and its estuary, and subsequent sediment dispersal in the East China Sea. Geomorphology. 179, 126-140.

Milliman J.D., 1997. Blessed dams or damned dams, Nature. 386, 325-327.

Milliman, J.D., Shen, H.T., Yang, Z.S., Meade, R.H., 1985a. Transport and deposition of river sediment in the Changjiang estuary and adjacent continental shelf. Cont. Shelf. Res. 4, 37-45.

Milliman, J.D., Beardsley, R.C., Yang, Z.S., Limeburner, R., 1985b. Modern Huanghe-derived muds on the outer shelf of the East China Sea: identification and potential transport mechanisms. Cont. Shelf. Res. 4, 175-188.

Niino, H., 1961. Sediments of shallow portions of East China Sea and South China Sea. Geol. Soc. Am. Bull. 72, 731-762.

Qin, Y.S., Zhao, Y.Y., Chen, L.R., Zhao, S.L., 1996.Geology of the East China Sea. Science Press, Beijing.

Shen, H.T., Li, J.F., Zhu, H.F., Zhou, F.G., 1986. Transport of the suspended sediments in the Changjiang Estuary (in Chinese). Journal of Sediment Research. 1, 1-13.

Shepard, F.P., 1932. Sediments of the continental shelves. B. Geol. Soc. Am. 43, 1017-1040.

Shi, B.W., Yang, S.L., Wang, Y.P., Bouma, T.J., Zhu, Q., 2012. Relating accretion and erosion at an exposed tidal wetland to the bottom shear stress of combined current-wave action. Geomorphology. 138, 380-389.

Smith S. E., Abdel-Kader A., 1988. Coastal erosion along the Egyptian Delta, Journal of Coastal Research. 4, 245-255.

Sternberg, R.W., Larsen, L.H., Miao, Y.T., 1985. Tidally driven sediment transport on the East China Sea continental. Cont. Shelf. Res. 4, 105-120.

$\mathrm{Wu}, \mathrm{H} ., 2014$. A study on erosion potential of the Yangtze subaqueous delta. Dissertation for master's Degree. East China Normal University. 90 pp. 
Wu, H., Deng, B., Yuan, R., Hu, J., Gu, J. H., Shen, F., Zhu, J.R., Zhang, J., 2013. Detiding measurement on transport of the Changjiang-derived buoyant coastal current. J. Phys. Oceanogr. 43, 2388-2399.

Xu, K.H., Li, A.C., Liu, J.P., Milliman, J.D., Yang, Z.S., Liu, C.S., Kao, S.J., Wan, S.M., $\mathrm{Xu}$, F.J., 2012. Provenance, structure, and formation of the mud wedge along inner continental shelf of the East China Sea: A synthesis of the Yangtze dispersal system. Mar. Geol. 291-294, 176-191.

Xue, Z., Liu, J.P., Demaster, D., Nguyen, L.V., Ta, O.T.K., 2010. Late Holocene Evolution of the Mekong Subaqueous Delta, Southern Vietnam. Mar. Geol. 269, 46-60. Yang, S.L., Milliman, J. D., Li, P.,Xu, K., 2011. 50,000 dams later, Erosion of the Yangtze River and its delta. Global Planet. Change. 75, 14-20.

Yankovsky, A. E., Chapman,D. C., 1997. A simple theory for the fate of buoyant coastal discharges. J. Phys. Oceanogr., 27, 1386-1401.

Zhu, J., Chen, C., Ding, P., Li, C., Lin, H., 2004. Does the Taiwan warm current exist in winter? Geophys. Res. Lett. 31, doi:10.1029/2004GL019997.

Acknowledgments. The authors thank the crew members of the research vessel Runjiang. We thank Dr. Rui Yuan and Mr. Guangfu Luo for their assistance in sampling and data collection. The research is funded by the National Science Foundation of China (grant no.41130856, 41271519, and 41021064).The winter wind data for the calculation of the coastal current duration was from the ECMWF (http://apps.ecmwf.int). 


\section{Figure captions}

477

478 Figure 1. Study area and station locations. Shaded areas indicate the surface suspended 479 480 sediment concentration (SSC, $\mathrm{mg} / \mathrm{L}$ ) distributions, with the contour lines parallel with the isobaths. Red dashed rectangle indicates the morphological investigation areas, modified from Yang et al., 2011. The inset shows the bathymetry of the East China Sea and the main ocean currents (blue arrow: The Min-Zhe Coastal Current (MZCC); red arrow: Taiwan Warm Current (TWC); black arrow: Yellow Sea Coastal Current (YSCC). The red bold line across the Yangtze subaqueous delta indicates the locations of the subbottom profile).The profile in the bottom shows a broad Holocene subaqueous delta mud wedge (blue) with a thickness of 20-40 m. The map created using ArcGIS-Esri.

Figure 2. Panel A-F: Integrated de-tidal longshore and cross-shore sediment flux $\left(\mathrm{g} / \mathrm{m}^{2} \mathrm{~s}\right)$. Distribution of $(\mathrm{A})$ salinity, (B) temperature $\left({ }^{\circ} \mathrm{C}\right),(\mathrm{C})$ suspended sediment concentration $(\mathrm{SSC}, \mathrm{mg} / \mathrm{L})$ in the cross-shelf profile from sites 1 to 8 . (D) De-tidal longshore current $(\mathrm{cm} / \mathrm{s})$. (E) De-tidal longshore sediment flux $\left(\mathrm{g} / \mathrm{m}^{2} / \mathrm{s}\right)$. Southward longshore current and sediment transport of The Min-Zhe Coastal Current (MZCC) presents at a water depth of $<40 \mathrm{~m}$, whereas the Taiwan Warm Current (TWC) flows northward at $>40 \mathrm{~m}$. (F) De-tidal cross-shore sediment flux $\left(\mathrm{g} / \mathrm{m}^{2} / \mathrm{s}\right)$. Seaward transport was found at a water depth of $<20 \mathrm{~m}$, and onshore mobilization was present at a water depth of $>20 \mathrm{~m}$.

Figure 3. Panel A-C: Suspended sediment concentration fluctuation during tidal cycles for sites 0 to 2 (A, B, and C share the same scale bar) from mooring observations. Black 
arrows indicate current vectors. The arrow direction shows the planar direction of the current, up for northward and right for eastward.

Figure 4. Cross-shelf transection along ECD1-4. Distribution of (A) salinity, (B) temperature $\left({ }^{\circ} \mathrm{C}\right)$, and $(\mathrm{C})$ suspended sediment concentration $(\mathrm{SSC}, \mathrm{mg} / \mathrm{L})$ in the cross-shelf profile from ECD 1 to 4.

Figure 5. Cross-shelf transection along ECB1-6. Distribution of (A) salinity, (B) temperature $\left({ }^{\circ} \mathrm{C}\right)$, and $(\mathrm{C})$ suspended sediment concentration $(\mathrm{SSC}, \mathrm{mg} / \mathrm{L})$ in the cross-shelf profile from ECB 1 to 6.

Figure 6. The coastal erosion or accumulation change in the last 60 years. (A) Historical change of the Yangtze River sediment discharge. The data were obtained from the Yangtze River Water Resource Commission at Datong hydrographic station. (B) The Three Gorges Dam (TGD) reservoir maximum water level above sea-level under different operational conditions. (C) Predicted alongshore coastal sediment transport. The winter wind data for the calculation of the coastal current duration was from the ECMWF. The wind data before 2001 was calculated using a 12-year average from 2001 to 2013. (D) Predicted delta accumulation/erosion. The data was estimate from predicted alongshore coastal sediment transport and Yangtze River sediment discharge. The blue bar suggests accumulation and the red bar indicates erosion. (E) Measured morphological sedimentary change (billion $\mathrm{m}^{3} / \mathrm{year}$ ) in the Yangtze subaqueous delta, the area is shown in Figure $1\left(1300 \mathrm{~km}^{2}\right)$, and data were collected from Yang et al., 2011. The blue bar suggests accumulation and the red bar indicates erosion. 
Figure 1.

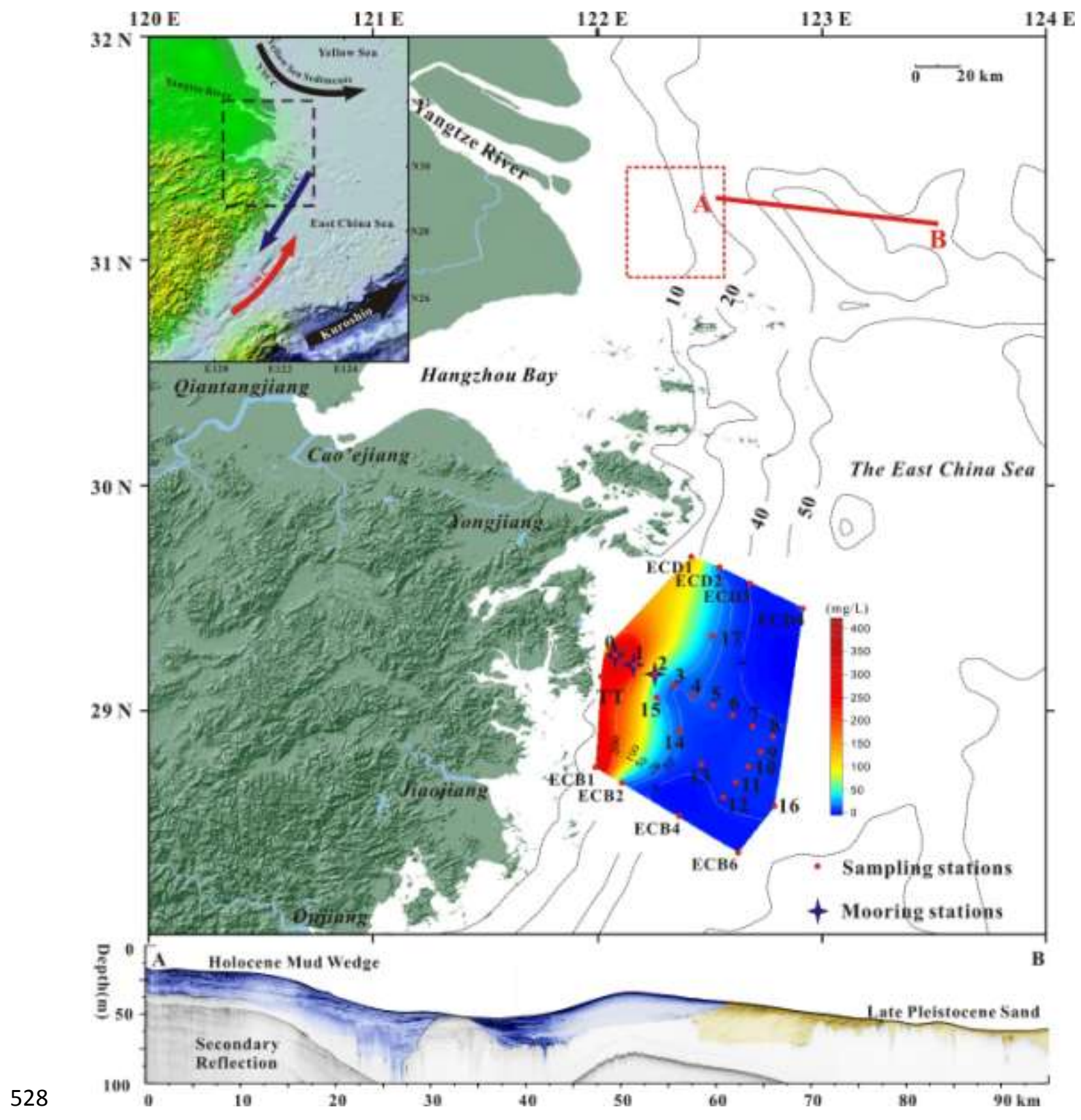


535 Figure 2.

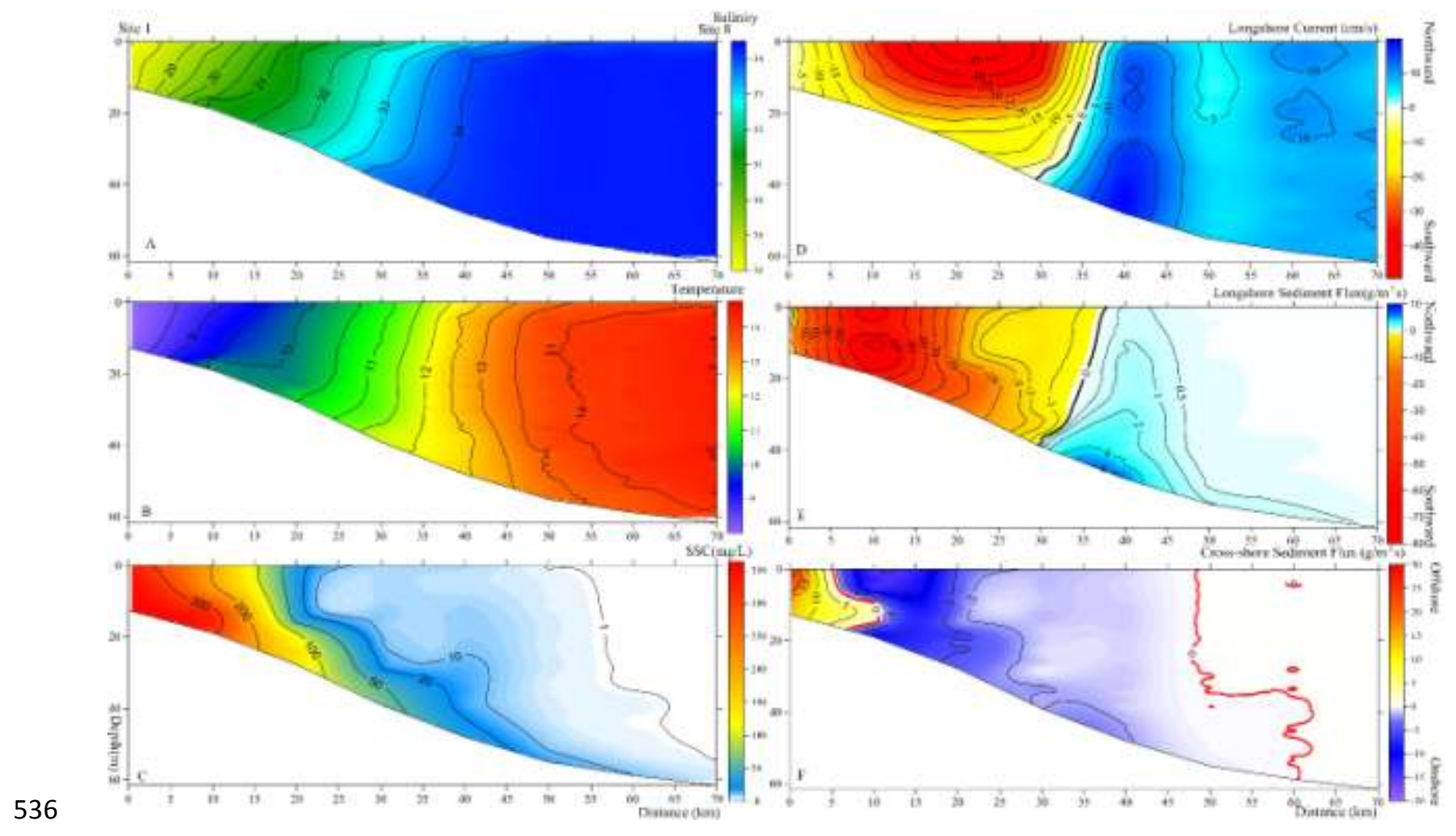

537

538

539

540

541

542

543

544

545

546

547 
Figure 3.
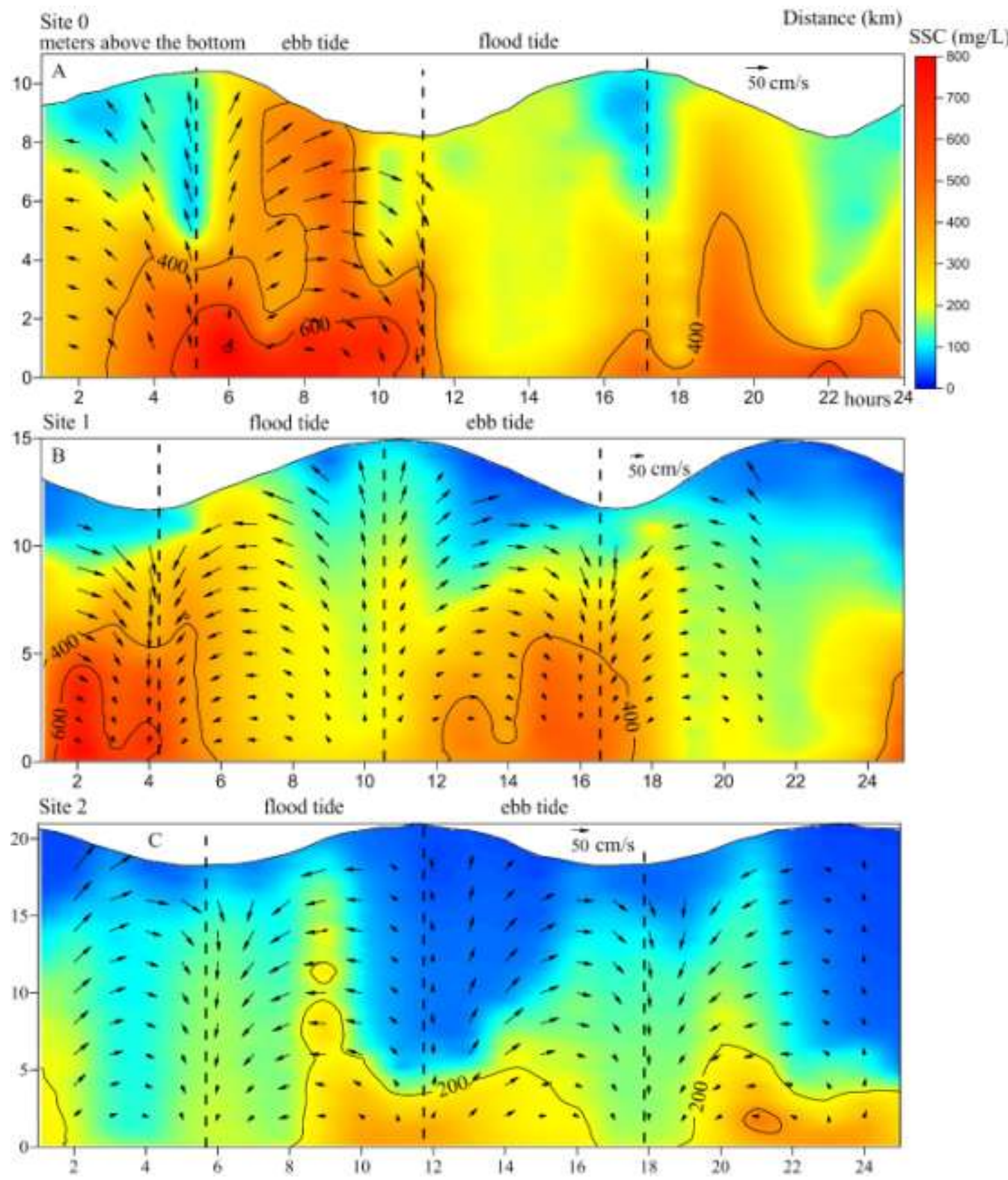
Figure 4.
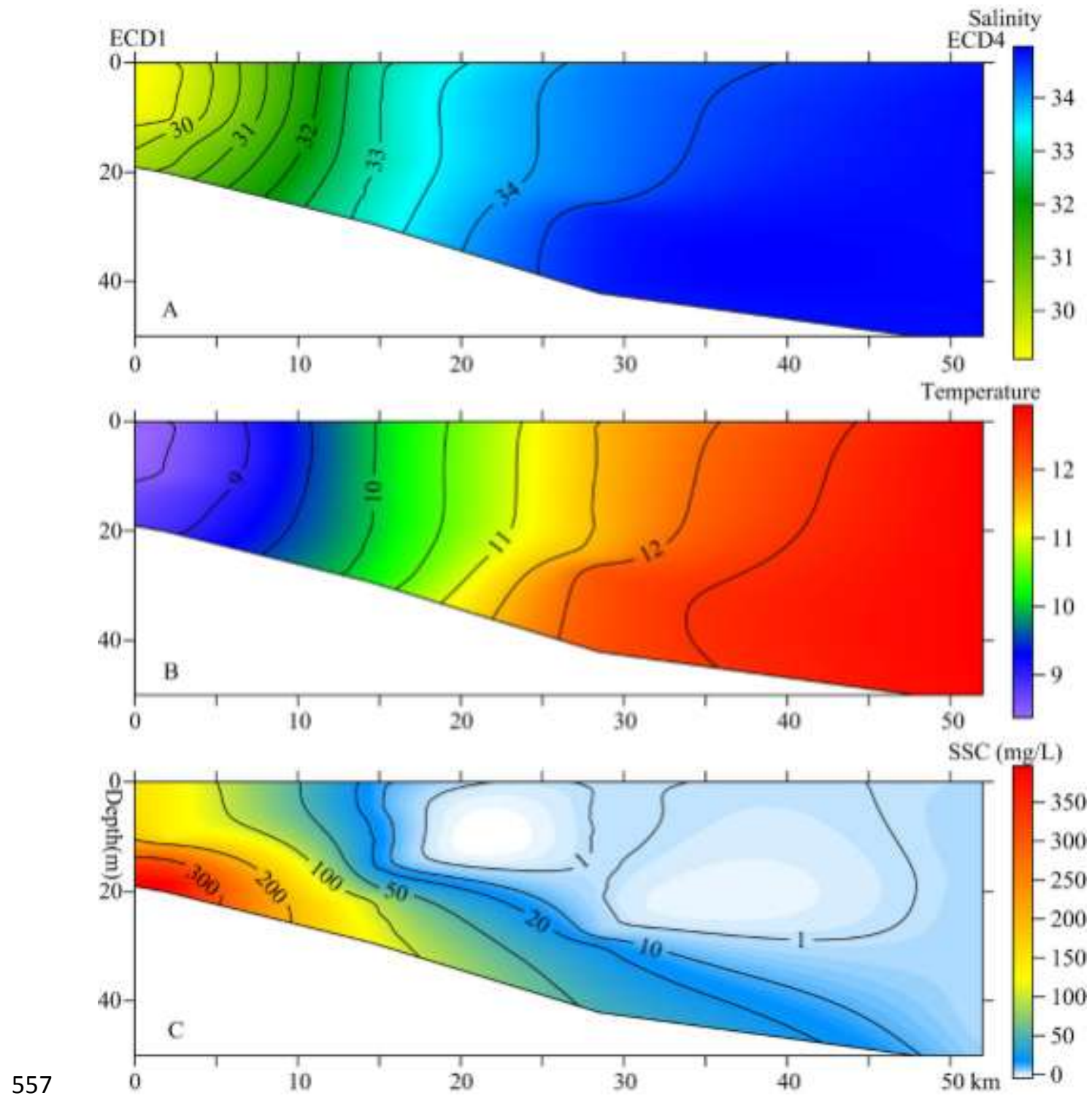

558

559

560

561

562

563 
Figure 5.
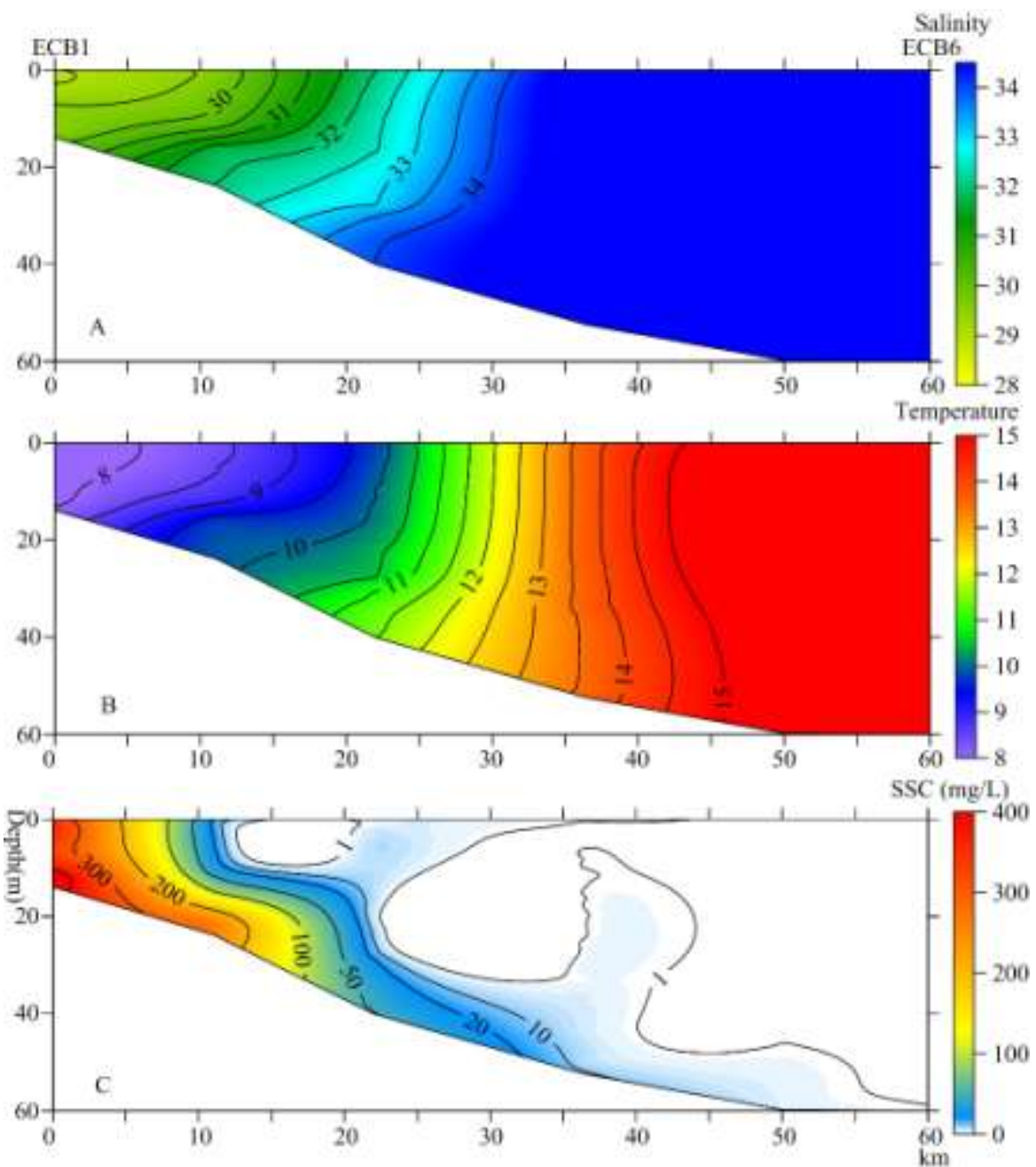

566

567

568

569

570

571

572

573

574

575 
Figure 6.
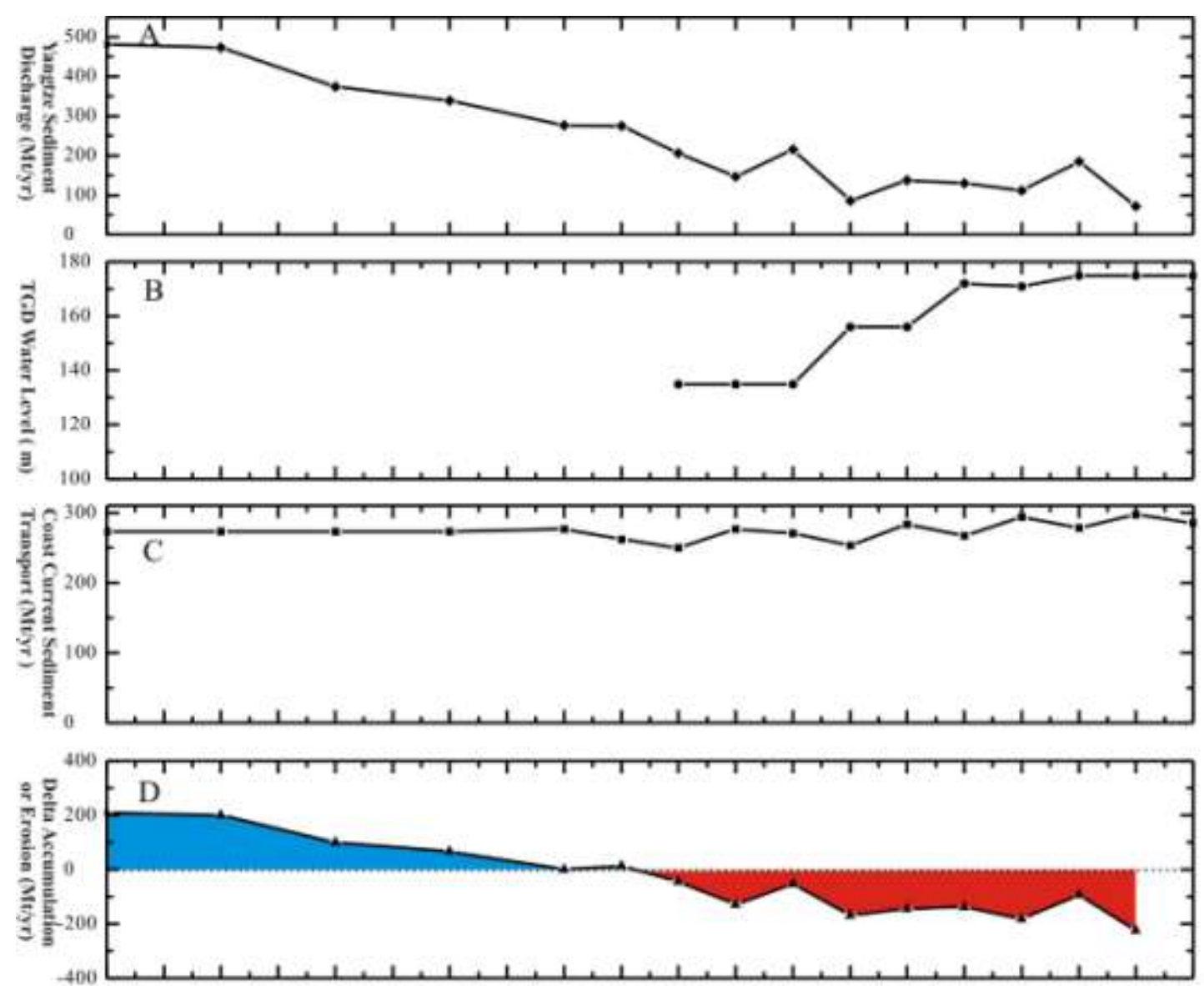

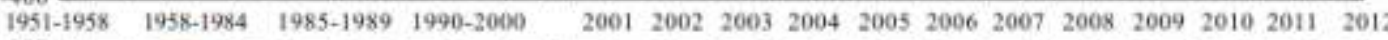

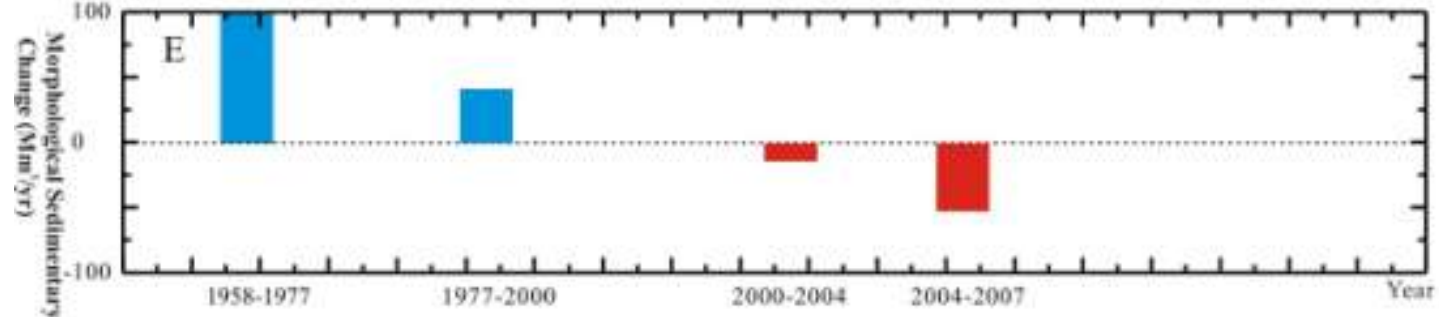

